\title{
Notas y comentarios
}

Presentación del libro Cincuenta años de investigación urbana y regional en México, 1940-1991

\section{Gustavo Garza}

Homenaje a Luis Unikel

En 1970, recién egresado de la maestría en economía de El Colegio de México, me introduje al tema del desarrollo urbano gracias a la oportunidad brindada por Luis Unikel, que entonces coordinaba el proyecto de investigación llamado El proceso de urbanización en México. Consciente de mi total desconocimiento sobre el tema, primero me confió la realización de uno de los capítulos de corte económico $y$, una vez terminado y publicado, me encargó otros dos del mismo tipo y el capítulo 10, que realicéijunto con Crescencio Ruiz y el propio Unikel. El libro que presenta los resultados de dicho proyecto se concluyó en 1974 y salió publicado en 1976. Mi participación en el trabajo me permitió iniciarme en el estudio de la economía urbana, especialidad que he desarrollado durante un periodo de 26 años y que creo haber llegado a medio entender.

Cuando estaba en Brasil en 1981 durante un periodo sabático, se me comunicó la inesperada y prematura muerte de Luis Unikel. Hemos querido que en 1996, cuando se cumplen 15 años de su deceso, la publicación del libro Cincuenta años de investigación urbana y regional en México nos reúna para recordar a quien fuera, y con su obra continúa siendo, uno de los autores más significativos de esta disciplina en México. Me permitiré sintetizar únicamente el prólogo del trabajo que ahora se presenta, para comentar con cierto detalle la obra principal de Unikel, a manera de un modesto homenaje a su memoria.

El libro Cincuenta años de investigación urbana y regional en México se propone describir la evolución de las publicaciones realizadas en la disciplina durante el periodo de 1940-1991, tomando como base 1831 libros y artículos que incorporan como material de análisis los ámbitos urbano y regional, agrupados dentro de los siguientes rubros: sociología, antropología, urbanismo, demografía, geografía, historia, economía, planificación y medio ambiente. Partiendo de una base de 
datos bibliográficos integrada por 1831 publicaciones, éstas se clasifican según las líneas de investigación, el nivel de análisis urbano o rural, el tipo de publicación y el lugar de adscripción del investigador. Considerando la periodización utilizada para su análisis resultó el siguiente capitulado:

Capítulo 1: "Albores de la investigación territorial en México".

Capítulo 2: "Lo urbano y regional como ecología humana, 1941$1960 "$.

Capítulo 3: "La investigación urbana dentro del proceso global de desarrollo, 1961-1970".

Capítulo 4: "Institucionalización de la investigación espacial, 1971-1980". $1991 "$.

Capítulo 5: "El auge de la investigación urbana y regional, 1981-

Capítulo 6: "Conclusiones: dependencia metodológica de la investigación urbana y regional en México".

Una parte importante del trabajo la constituye el apéndice bibliográfico que incluye las 1831 referencias mencionadas anteriormente. Para facilitar su consulta, éstas se ordenaron alfabéticamente según el nombre del autor, especificándose la disciplina en que fueron clasificadas.

Este esfuerzo de presentar una imagen general del estado actual de la investigación urbana y regional en México adolece de una serie de limitaciones. En primer lugar, el intento por incluir todas las investigaciones relevantes implicó la imposibilidad de revisarlas adecuadamente, pues el dedicar dos días al examen de cada una habría implicado 10 años de trabajo, así como la elaboración de dos mil cuartillas si se hubiera escrito una para cada publicación. En segundo lugar, no se considera haber logrado una recopilación exhaustiva de las publicaciones existentes pero, en el peor de los casos, se tiene un amplio conjunto altamente representativo de la temática de los trabajos publicados. Me permito ofrecer disculpas a los autores que consideren que no se han incluido todas sus publicaciones, hecho que debe atribuirse a que no están registradas en las fuentes utilizadas, a que no incorporan explícitamente el elemento territorial, o a que se consideraron únicamente las más relevantes: en el caso de un servidor, se incluyen alrededor de un tercio de sus publicaciones. En tercer lugar, y lo que es más importante, fue imposible intentar el análisis metodológico de 
los trabajos porque esto hubiera implicado mucho tiempo y por mi incapacidad para hacerlo. Las fuentes de las referencias fueron: las bibliografias especializadas existentes, el catálogo de la biblioteca de El Colegio de México, algunos bancos electrónicos (Secobi, Docpal, principalmente), así como otras obras de consulta. Las referencias fueron procesadas para la construcción de los cuadros estadísticos por medio del programa Microisis.

A pesar de sus limitaciones, no hubiera sido posible realizar el trabajo sin el apoyo de una serie de personas e instituciones. Araceli Damián fue la responsable del acopio de las referencias bibliográficas, por lo cual le quedo muy agradecido. Francisco Covarrubias, en su calidad de subsecretario de Desarrollo Urbano de la anterior Sedue, apoyó decididamente la investigación, por lo cual le quedamos en deuda. El director del cEDDu, Gustavo Cabrera Acevedo, otorgó en todo momento el apoyo institucional requerido para la buena marcha del proyecto, por lo que le ratificamos en esta oportunidad nuestra gratitud. Extendemos nuestro agradecimien to a la Unidad de Cómputo de El Colegio por su invaluable apoyo en el procesamiento electrónico del banco de referencias, así como al Departamento de Publicaciones por enfrentar la siempre árdua labor que representa la publicación de un libro. Finalmente, agradecemos la paciente dedicación de María Estela Esquivel en el procesamien to electrónico del texto y la bibliografía.

El capítulo sobre los años setenta presenta 455 publicaciones, de las cuales $19.3 \%$ abordó temas de demografía, $18.2 \%$ de sociología y antropología, $15.2 \%$ de urbanismo, $14.3 \%$ de economía y $10.3 \%$ de historia. Sobresale con mucho la publicación en 1976 del libro El desarrollo urbano de México. Diagnóstico e implicaciones futuras, de Luis Unikel en colaboración con Crescencio Ruiz Chiapetto y Gustavo Garza. Me propongo recordar a continuación las características de la obra principal de Unikel, destacando su importancia en el desarrollo de la disciplina urbano-regional en México.

El objetivo fundamental del proyecto fue la realización de un exhaustivo diagnóstico macroestadístico del desarrollo urbano de México en los ámbitos nacional, regional y urbano, así como el análisis de algunas de sus más importantes interrelaciones económicas y demográficas. Su propósito inicial fue deslindar la urbanización del desarrollo económico, para evitar caer en la maraña de confusiones de aquella época (y que al parecer se extienden hasta nuestros días) sobre las características y vínculos entre ambos procesos. Se consideró a la urba- 
nización como parte integrante del proceso global de cambio socioeconómico, pero constituida por el aumento del tamaño y número de ciudades, así como del porcentaje de la población urbana respecto a la total. De esta manera, se optó por un corte metodológico que centrara el análisis de la urbanización en sus características ecológicas y demográficas, sin desconocer los efectos concomitantes de la transformación de la estructura y las superestructuras rurales en urbanas. Así, se decidió cubrir el requerimiento más urgente de la discipina urbano-regional en el país, que era, precisamente, conocer con rigor científico la fenomenología de su proceso de urbanización.

La metamorfosis rural-urbana se manifiesta nítidamente en el aumento ininterrumpido del porcentaje de población urbana del país en el periodo que se analiza: de $10.5 \%$ en 1960 aumentó a $44.7 \%$ en 1970. Según las proyecciones del libro, para 1980 el porcentaje creció a $52.8 \%$ y a $60.6 \%$ en 1990 , mientras que con las cifras censales se estima en $56.6 \%$ y $60.8 \%$, respectivamente. La cifra proyectada para 1990 sólo difiere en dos décimas de la censal $(0.3 \%)$, mientras que la diferencia de $6 \%$ en la de 1980 se debe más bien a la conocida sobreestimación censal de la población de algunas ciudades, principalmen-

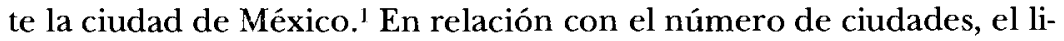
bro pronostica 258 en 1980 , cuando en realidad hubo 229 ; y 378 en 1990, cuando según el censo, existieron 309. La diferencia de la población total urbana pronosticada y la censal es de $6.1 \%$ y $12.2 \%$, respectivamente.

Después de analizar detalladamente las características de la urbanización por regiones y entidades federativas (capítulo 2); delimitar el sistema y los subsistemas de las ciudades (capítulo 3); el carácter metropolitano de las principales ciudades del país (capítulo 4); las funciones económicas de las urbes (capítulo 5); y el desarrollo económico regional y la urbanización (capítulo 6), se llega al estudio de los determinantes de la migración rural-urbana (capítulo 7). Ésta constituye una mediación fundamental entre el desarrollo económico y el crecimiento urbano. En la investigación se estima que el monto de migrantes entre el campo y la ciudad para 1940-1970 fue de 6.2 millones de personas, lo

${ }^{1}$ Según el censo de 1980 la póblación del Área Metropolitana de la ciudad de México fue de 14.4 millones de habitantes, pero al ajustarla por considerar que está sobrestimada se tienen 12.8 millones de habitantes. Con sólo este ajuste el nivel de urbanización de 1980 se reduce de $56.2 \%$ a $54.5 \%$ y la diferencia con la proyección del libro es únicamente de 3.2 por ciento. 
cual explica el elevado ritmo de la urbanización en el periodo. Es importante destacar que alrededor de $50 \%$ del éxodo migratorio se dirigió a la ciudad de México, lo cual dio lugar a la superconcentración económica y demográfica en la capital del país y al proceso de expansión de un conjunto creciente de metrópolis, que se incrementaron de 12, que el libro registró para 1970, a 25 en 1990.

En el extremo opuesto, se detectó que la mayoría de las ciudades y regiones se distanciaban cada vez más de los dinámicos polos metropolitanos, contra lo establecido en las teorías regionales convencionales que suponen la reducción de las disparidades territoriales a medida que avanza el desarrollo económico. Se recomendó el diseño de una política de desarrollo urbano y regional que hiciera posible el aprovechamiento de los recursos naturales y la democratización del reparto de la riqueza social, enfatizando la necesidad de atender a las regiones más rezagadas mediante el estímulo de las actividades con mayores ventajas comparativas. Sin embargo, en la medida en que se desarrollen estas regiones requerirán menos fuerza de trabajo, la cual tenderá a migrar hacia las ciudades. La verdadera batalla contra el desempleo y subempleo deberá desarrollarse indefectiblemente dentro del sistema urbano.

El capítulo final del libro analiza las políticas urbano-regionales del gobierno federal a partir de 1915. Al contrastarlas con la realidad multidimensional del desarrollo urbano de México, se sugiere la conveniencia de elaborar una política urbana capaz de regular y modificar las manifestaciones negativas de la urbanización antes de que sus soluciones resulten más difíciles y costosas, como lamentablemente ha ocurrido con la contaminación atmosférica en la ciudad de México. En esta dirección, en el último párrafo del libro se afirma:

Los resultados de esta investigación pretenden ser un modesto punto de partida que auxilie en la elaboración de una política de tal naturaleza, la cual, además, debe ser un valioso instrumento en las políticas económicas nacionales que persigan racionalizar el crecimiento económico del país.

Desde la aparición del libro en 1976 se han realizado cuatro programas nacionales de desarrollo urbano, pero no se puede considerar que reúnan los requerimientos sustantivos y procesales necesarios para cumplir tal tarea. Tendremos que continuar esperando. Quizás ésta fue la razón por la cual Luis Unikel, una vez terminado el estudio 
aquí comentado, se dedicó a trabajar sobre la planeación urbana en colaboración con Alian Lavell y Pedro Pírez, labor que desempeñó hasta los últimos días de su vida.

Con Lavell y Pírez realizó el estudio "El Estado y la cuestión regional en México" (1978); con el primero escribió el artículo "Bases, características y contradicciones de la presente estrategia de desarrollo urbano regional en México" (1979) y él solo escribió "Regional Development Policies in Mexico", que se publicó en un libro editado por Alan Gilbert y dedicado a su memoria, que apareció en 1982. Éste fue su artículo póstumo donde, después de analizar las políticas y planes territoriales en el país, concluye: "No obstante, los estudios, planes y programas han sido formulados en un 'vacío social', sin haberse evaluado cuidadosamente la viabilidad económica, política y social de las medidas propuestas".

Además de su obra publicada, dentro de la cual sobresale la coordinación del libro antes mencionado (considerado como la vanguardia en el horizonte de la investigación urbana y regional en México y que en buena medida continúa siéndolo), fue central la participación de Luis Unikel en la fundación en 1976 del Área de Desarrollo Urbano y la Maestría de Estudios Urbanos, ambas institucionalizadas con la creación del actual Centro de Estudios Demográficos y de Desarrollo Urbano. Los diez investigadores que actualmente forman dicha área han continuado la labor de investigación iniciada por él, y han publicado algunas decenas de libros y centenas de artículos en la especialidad. Respecto a la docencia, en la actualidad cursa la Maestría en Estudios Urbanos la décima generación de estudiantes, y con ella habrán egresado 163 estudiosos de las cuestiones urbanas y regionales.

Finalmente cabría afirmar que el reto que en México enfrenta todo el cuerpo de investigadores especializados en la denominada ciencia regional es avanzar en el diseño de nuevos enfoques metodológicos que permitan profundizar en la característica espacial de los procesos sociales, económicos y políticos que determinará el futuro de México. Tal es la conclusión general del libro que esta noche se pone a la distinguida consideración de todos ustedes. Poder avanzar en esa dirección será el más digno homenaje a la labor visionaria de Luis Unikel. 


\section{Bibliografía}

Garza, Gustavo (1996), Cincuenta años de investigación urbana y regional en México, 1940-1991, México, El Colegio de México.

Unikel, Luis (1982), "Regional Development Policies in Mexico", en Alan Gilbert (ed.), Urbanization in Contemporary Latin America, Nueva York, John Wiley \& Sons.

__ y Alian Lavell (1979), "Bases, características y contradicciones de la presente estrategia de desarrollo urbano regional en México", Seminario sobre Estrategias Nacionales de Desarrollo Regional, llpes, Iss, Ildls, Uniandes, Bogotá, 17 al 21 de septiembre.

Lavell, Alian, Pedro Pírez y Luis Unikel (1978), "El Estado y la cuestión regional en México", Seminario sobre la Cuestión Regional en América Latina, El Colegio de México, 24-29 de abril. 


$$
\text { , }
$$

